\title{
Veterans walk to beat back pain: study rationale, design and protocol of a randomized trial of a pedometer-based Internet mediated intervention for patients with chronic low back pain
}

Sarah L Krein ${ }^{1,2^{*}}$, Tabitha Metreger ${ }^{1}$, Reema Kadri ${ }^{1}$, Maria Hughes ${ }^{1}$, Eve A Kerr ${ }^{1,2}$, John D Piette ${ }^{1,2}$, Hyungjin Myra Kim ${ }^{1,3}$, Caroline R Richardson ${ }^{1,4}$

\begin{abstract}
Background: Chronic back pain is a significant problem worldwide and may be especially prevalent among patients receiving care in the U.S. Department of Veterans Affairs healthcare system. Back pain affects adults at all ages and is associated with disability, lost workplace productivity, functional limitations and social isolation. Exercise is one of the most effective strategies for managing chronic back pain. Yet, there are few clinical programs that use low cost approaches to help patients with chronic back pain initiate and maintain an exercise program.

Methods/Design: We describe the design and rationale of a randomized controlled trial to assess the efficacy of a pedometer-based Internet mediated intervention for patients with chronic back pain. The intervention uses an enhanced pedometer, website and e-community to assist these patients with initiating and maintaining a regular walking program with the primary aim of reducing pain-related disability and functional interference. The study specific aims are: 1) To determine whether a pedometer-based Internet-mediated intervention reduces pain-related functional interference among patients with chronic back pain in the short term and over a 12-month timeframe. 2) To assess the effect of the intervention on walking (measured by step counts), quality of life, pain intensity, pain related fear and self-efficacy for exercise. 3) To identify factors associated with a sustained increase in walking over a 12-month timeframe among patients randomized to the intervention.
\end{abstract}

Discussion: Exercise is an integral part of managing chronic back pain but to be effective requires that patients actively participate in the management process. This intervention is designed to increase activity levels, improve functional status and make exercise programs more accessible for a broad range of patients with chronic back pain.

Trial Registration Number: NCT00694018

\section{Background}

Chronic pain, especially low back pain, is a significant problem worldwide, with one fourth of adults in the U.S. reporting low back pain in the past three months and about one-half reporting back pain during a given year [1-3]. Low back pain is generally considered chronic when it persists for longer than three months

\footnotetext{
* Correspondence: skrein@umich.edu

'VA Ann Arbor Health Services Research and Development Center of

Excellence, VA Ann Arbor Healthcare System, Ann Arbor, MI, USA

Full list of author information is available at the end of the article
}

[4], and the longer the pain persists the greater the risk for long-term disability [5]. Chronic back pain affects both younger and older adults with potentially significant consequences regardless of age. Among younger adults, chronic back pain is associated with disability, unemployment and lost productivity, whereas for older adults chronic back pain is associated with functional limitations, economic difficulty and social isolation [5-7]. Chronic pain-related conditions are among the major drivers of healthcare costs in the U.S. and chronic low 
back pain is the single most costly condition in terms of work loss [8].

Pain affects many patients using the U.S. Department of Veterans Affairs (VA) health care system [9-12], and may be even more prevalent in VA than in the general population. Fifty to seventy percent of VA general medicine patients suffer from chronic pain, defined as pain persisting for six or more months $[9,11]$, with back pain the most commonly reported type of pain [13]. Back pain is also one of the most prominent complaints among Veterans returning from the conflicts in Iraq and Afghanistan [14] and the number of VA users with a low back pain diagnosis appears to be rising [15].

\section{Management of Chronic Back Pain}

The high prevalence, high cost and negative consequences of chronic back pain underscore the significant need for effective and efficient approaches for managing this condition. Strategies for managing chronic back pain range from traditional medical management approaches (e.g., pharmacotherapy) and self-management programs to interventional pain management techniques and complementary and alternative medicine [16-22]. There is little, if any, sound evidence to support the use of surgery or other invasive interventions for most patients with chronic low back pain $[4,23,24]$ and relatively strong evidence to support the effectiveness of exercise therapy, intensive multidisciplinary pain programs, and certain psychological interventions $[16,19,22,25]$.

\section{Exercise and Chronic Back Pain}

Staying active and exercise therapy can prevent recurrence, reduce pain, improve functional status, and decrease disability for patients with chronic back pain [16,19,21,26-28]. A meta-analysis by Hayden and colleagues [17] suggested that the most effective strategy for improving back pain consisted of an individually designed exercise program that included home-based supervision and a relatively intensive exercise regimen. Yet, the design, delivery and evaluation of an exercise program that incorporates these "ideal" components have yet to be accomplished.

Research also shows that a variety of exercise programs including yoga as well as aerobic and strengthening exercises result in both clinically and statistically significant improvements in outcomes for patients with chronic back pain [16,21,26-28]. However, most of the interventions studied have been short term, with outcomes measured within the first six months. While such studies may be appropriate for testing the efficacy of exercise among patients with chronic back pain under ideal circumstances, the intensity and required resources for these programs are likely to limit their sustainability and potential reach in real-world practices $[17,21,28,29]$. Thus, we still lack efficient and effective strategies for promoting exercise therapy among patients with chronic back pain or ways to use exercise as part of a treatment program [13,30-32].

A recent review article found only low to moderate evidence supporting walking as an effective intervention for low back pain [33]. Yet, the article also highlights the paucity of research in this area, with only four studies identified for the review and three of the four judged as being of poor methodological quality. The authors therefore conclude that further research on the role of walking as a primary intervention for managing chronic low back pain is needed.

\section{Conceptual Framework}

Given the challenges just described, we have developed an intervention that uses generally available tools and a relatively low cost approach to help patients with chronic back pain initiate and maintain an exercise program. The conceptual framework shown in Figure 1 summarizes the components of the intervention and how it is expected to influence pain-related disability or functional interference as well as other health outcomes. The intervention has three general components, each of which is described below along with the supporting rationale. First, the intervention uses an enhanced pedometer to promote walking directly through feedback, goal setting and monitoring. Walking is considered an ideal exercise since it is something that most anyone can do regardless of their health condition and does not involve the use of specialized equipment. Second, this intervention promotes walking through the use of a website that includestargeted content to enhance exercise self-efficacy. The website also contains materials to reinforce other important activities for managing chronic back pain, such as the use of strengthening and stretching exercises. The third component of the intervention is an e-community to provide social support, both peer and professional, that encourages patients to initiate and adhere to a walking program. We believe that more walking will contribute to improvements in function among patients with chronic back pain through multiple mechanisms, including improvements in mood, weight loss and by combating pain-related fear and selfprotective behaviors, which can lead to reduced muscle tone, increased pain perceptions and functional disability.

\section{Key Intervention Components \\ Pedometers and walking programs}

Others have previously demonstrated the feasibility and safety of home-based walking programs for individuals with chronic health conditions, including chronic pain 


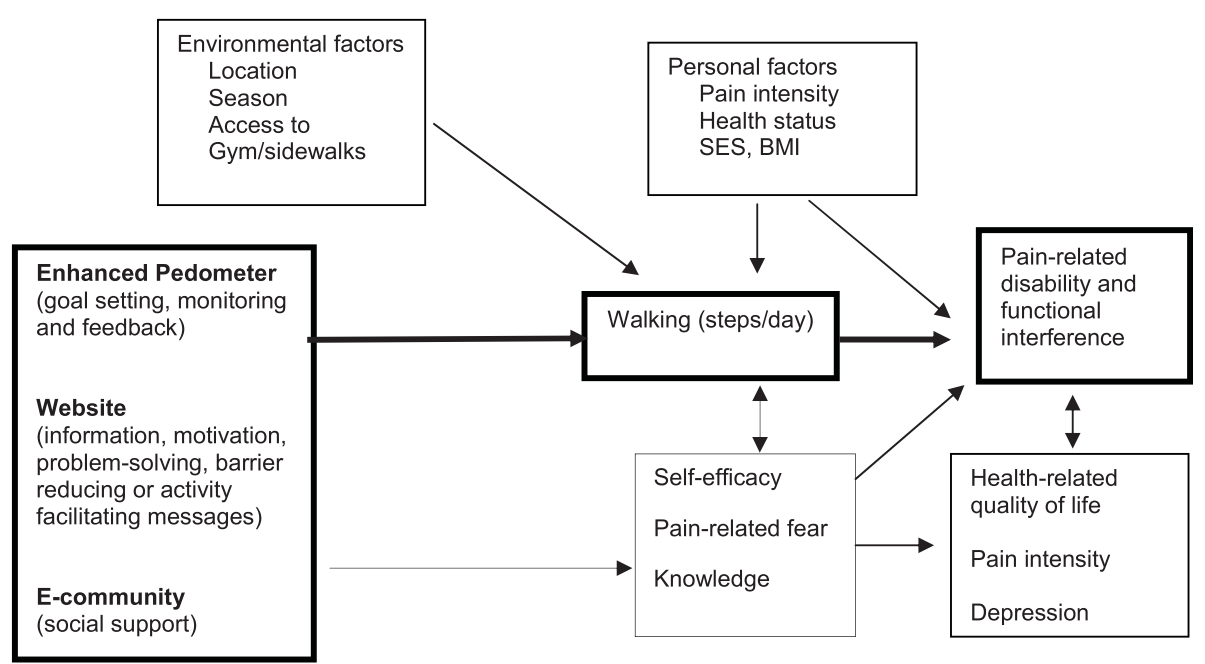

Figure 1 Study conceptual framework.

conditions [34-38]. Additionally, studies suggest that a majority of middle-aged and older adults prefer physical activity outside a formal setting [39], and that participation rates and maintenance of physical activity are generally better in supervised home-based programs $[17,40]$. The use of pedometers has become increasingly popular both as a way for individuals to monitor step counts and as an objective tool used by researchers to assess physical activity [41]. Pedometer-based walking programs can increase walking, at least in the short term, across a range of patient populations, including those at high risk for cardiovascular disease [36] and patients with mental health conditions $[42,43]$. Few studies, however, have examined the sustainability or effectiveness of a pedometer-based intervention on a longer-term basis or assessed the use of "enhanced" pedometers [43]. Whereas a simple pedometer provides instant feedback in the form of daily step counts, an enhanced pedometer provides detailed tracking of walking duration, automated step count logging and can be linked to a computer-based system to assist with goal setting and feedback on goal attainment. Goal setting and self-monitoring are key components in the process of self-regulation $[44,45]$. Facilitating achievable performance accomplishments through goal setting and feedback, reinforcing successful self-care activities and providing positive feedback when someone makes an effort to change their behavior are also part of skill development and enhancing self-efficacy, which are both key constructs of Social Cognitive Theory [44,46].

\section{Internet-mediated interventions}

Internet based programs are an increasingly popular option for delivering behavior change interventions [18,47-49]. The Internet provides a flexible, low cost communication vehicle that can play a key role in physical activity interventions by facilitating the exchange of information and by delivering encouraging or motivational messages to a large number of participants. A web-based platform can be used to deliver either tailored or static messages that target important socialcognitive processes such as fear avoidance or selfefficacy. Self-efficacy, which is the level of confidence in one's own ability to perform a task or specific behavior [46], has been linked to the initiation and maintenance of physical activity [50-52] and a number of desired outcomes including better health-related quality of life or better physical functioning even when physical symptoms may not significantly improve [53-55].

\section{E-communities and social support}

One of the challenges of Internet-based behavior change programs is keeping participants interested and engaged for a sufficient duration, which can be important to ensure a therapeutic benefit [56]. An e-community is one potentially promising strategy for enhancing participation rates and improving the effectiveness of the intervention $[18,56]$. An e-community is a way for participants to both send and receive messages and can be developed using e-mail, threaded forums (asynchronous messaging) or chat rooms (synchronous, real-time messaging). The primary purpose of the e-community is to provide peer and/or professional support, which is strongly associated with physical activity and other health behaviors [51,52]. Receiving social support can have a positive effect on health and behavioral outcomes [57], self-efficacy [53], and physical activity [58]. Providing support to others also can lead to improved health behaviors on the part of the helper [59] as well as improved health outcomes and function [60]. Although 
the most commonly studied method of enhancing social support is through group programs, many patients face difficulties attending regular face-to-face meetings or group-based activities [45]. In a healthcare system in which resources are limited and patients face geographic and other barriers to accessing services, traditional group programs may also place a significant burden on patients and the health system. In contrast, e-communities, can translate the underlying principles and benefits of social support into systems that are effective for large, diverse patient populations.

\section{Methods/Design}

This randomized controlled trial includes outcomes measured at baseline, 6 and 12 months (Figure 2). The goal is to investigate the efficacy of the intervention in assisting patients with chronic back pain with initiating and maintaining a regular walking program. The primary outcome is pain-related disability and functional interference. The study specific aims are:

Aim 1 To determine whether a pedometer-based Internet-mediated intervention reduces pain-related functional interference among patients with chronic back pain in the short term and over a 12-month timeframe.

Aim 2 To assess the effect of the intervention on walking (measured by step counts), quality of life, pain intensity, pain related fear, and self-efficacy for exercise.

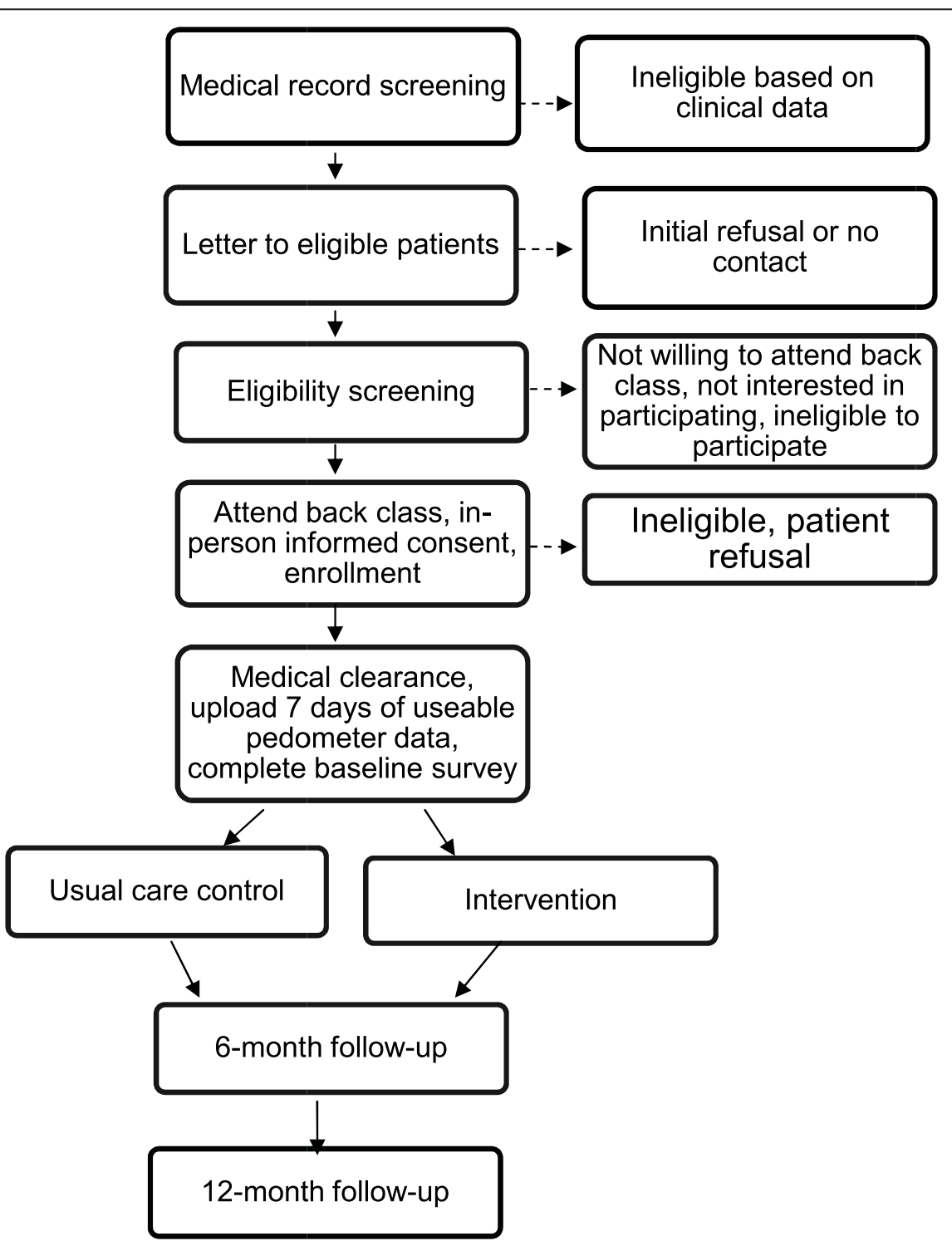

Figure 2 Flow chart describing study recruitment and enrollment process. 
Aim 3 To identify factors associated with a sustained increase in walking over a 12 -month timeframe among patients randomized to the intervention.

Patients with chronic back pain receiving care at a VA health care system are being recruited to participate in the study and are randomized to either enhanced usual care (control) or the pedometer-based Internet-mediated intervention. All participants are required to attend a general educational program ("back class") for individuals with chronic back pain. This ensures that all participants have a basic understanding of back mechanics and general strategies for managing back pain. Ethical approval for this study has been granted by the VA Ann Arbor Healthcare System human studies sub-committee.

\section{Eligibility Criteria and Identifying Eligible Patients}

Potential participants are identified both through provider referral to back class and through data obtained from the VA electronic medical record system. Specifically, these data are used to identify patients who had two or more outpatient encounters in the prior 12 months with a diagnosis of back pain with no neurologic findings (ICD-9-CM codes $724.2,724.5,846.0-846.9)$. To be eligible for the study participants must: 1 ) have back pain that has persisted for more than 3 months; 2) have a sedentary lifestyle (less than 150 minutes of physical activity per week); 3) have access to a computer on at least a weekly basis with an available USB port and Internet access; 4 ) be able to provide written informed consent; 5) be able to communicate in English; 6) be non-institutionalized; 7) be able to walk at least one block; and 8) report they are not pregnant. Prior to participation, eligible patients must attend back class and obtain medical clearance from a physician, which may be their primary care provider, cardiologist, physical medicine and rehabilitation or pain management physician.

\section{Back Class}

During back class, a physical therapist provides general education about back problems and strategies for managing back pain, with an emphasis on the importance of exercise (strengthening, stretching and aerobic) [materials available upon request]. During the class, patients practice strengthening and stretching exercises under the guidance of a physical therapist who adapts the exercises based on a patient's medical conditions. Up to 20 patients are scheduled per class, and each class takes approximately two hours.

\section{Patient Enrollment and Randomization}

During the enrollment process, written informed consent is obtained and patients complete a six-minute walk test. All participants then receive an enhanced pedometer and USB cable to allow them to upload their step counts to a secure study website. Participants receive general guidance about how to use the pedometer and specific instructions for uploading data. The pedometer used for this study is the Omron HJ-720ITC, which contains a dual axial accelerometer, an internal clock, enough memory to store 42 days of detailed time stamped step count data, and an embedded USB port. The Omron pedometer is accurate within 1 to $4 \%$ compared to directly observed step-counts [61]. Pedometers that use accelerometers to detect motion are more accurate than spring and magnet pedometers when used by obese participants [62] and can be worn in different places on the body (as a necklace, on the hip, in a shirt pocket, in a pants pocket). For each hour of the day, the pedometer records a time and date, total steps, bout steps (10 minutes or more of continuous movement), and an activity flag that indicates if the pedometer detected any movement at all during the hour. During enrollment, study participants are also provided with instructions (including a log-in name and password) for accessing the study website to complete surveys or report adverse events.

Following enrollment, participants are instructed to wear their pedometer for seven days with the read out on the pedometer covered. At the end of the seven days they are asked to upload their pedometer data for the first time so we can establish a baseline measurement. After completing a baseline survey, uploading seven days of useable pedometer data and receiving medical clearance the participant is flagged as active in the system, and the computer randomly assigns them to the intervention or control group. The participant then receives an e-mail message with their group assignment, instructions to upload on either a weekly (intervention) or monthly (control) basis, and is instructed to remove the sticker covering the pedometer face.

\section{Enhanced Usual Care}

Participants randomized to the control group, receive monthly e-mails asking them to upload their pedometer data. Those data are stored but not used for any further feedback to patients. Although the pedometer is an enhancement to what patients receive in standard practice, past studies suggest that pedometers in isolation are unlikely to result in a sustained increase in walking among generally sedentary individuals [43]. While control group participants are provided with log-on information for the study website, their access is limited to completing study surveys and reporting adverse events.

\section{Pedometer-Based, Internet Mediated Intervention}

The study intervention is based on the Stepping Up to Health program developed by Richardson and colleagues 
[63]. The intervention consists of three primary components (Figure 1). Active intervention participants receive weekly e-mail reminders to upload their pedometers, weekly individualized walking goals and full access to the study website. Specifically, each person in the intervention receives computer generated personal walking goals. The goals are sent to participants by e-mail on a weekly basis and are automatically adjusted to assist the individual with increasing his/her step count at a reasonable pace or help with countering negative thoughts and behaviors when a particular goal is not achieved. Besides receiving a new goal each week, participants receive graphical and written feedback about their progress toward their goals when they log into the study website (Figure 3). The graph shows a breakdown of steps by day, week and month, while the text informs the participant about their average step count for the week and how many days his or her goal has been met up until that day. For example, it might read, "You have met your walking goal on 3 of 7 days. Your average daily step count for the week is 3568." While the general intent is for the total step goals to increase over time and thus promote an increase in walking, because the goals are established based on the participant's own activity level the goals can also be lower from one week to the next. Resetting a goal at a lower level can be beneficial when trying to counter the potential negative reaction and sense of failure for participants who may not be achieving the higher goals or for participants who might need to be reminded to start low and go slow after a relapse or health event that may have led to a decreased step count in the prior period. Participants who are not uploading data weekly receive step goals based on the last time they uploaded and will have the same goal until new activity takes place.

The participant website is tailored according to gender and includes information and messages (e.g., motivation, time constraints) to promote walking and a healthy lifestyle. New motivational or informational messages addressing potential barriers to physical activity (e.g., weather) or issues related to diet or other health conditions (e.g., cardiovascular disease, diabetes) appear every other day. Brief updates about topics in the news or new research findings related to back pain or physical activity are generally posted on a weekly basis so the website content does not get stagnant. The website also includes the materials and hand-outs that participants received at back class as well as a video demonstrating the proper technique for the strengthening and stretching exercises taught during the class.

The e-community component of the intervention consists of a thread-based forum that allows participants to conduct asynchronous text-based discussions. Each participant selects a pseudonym in order to establish an on-line identity while maintaining privacy. Following work by Lorig et al. [18], the e-community is used to provide both peer and professional social support. The e-community allows intervention participants to post messages, which can include asking questions, making suggestions or sharing success stories. The messages are monitored by research staff, including a physical therapist who does not provide individual medical advice but can respond to questions or back pain related issues with general information based on the VA low back pain guidelines. The forum also serves as a venue for generating competitions among the intervention participants to encourage walking and meeting walking goals. An advantage of an electronic forum is that it can prevent e-mail overload and all postings can be monitored to prevent inappropriate messages or communication. Experience to date shows that inappropriate messages are rare.

\section{Monitoring and Reporting of Adverse Events}

The study includes several mechanisms for monitoring, troubleshooting and identifying the minority of patients for whom a relatively low intensity walking program is considered unsafe. Medical clearance is required and patients for whom walking is not a recommended activity, due to for example balance problems or cognitive impairment, are not eligible to participate. However, since we are trying to use relatively few exclusion criteria it is possible that some patients will be eligible but later develop signs or symptoms that suggest walking may no longer be a safe activity. Both intervention and control participants are encouraged to report adverse events including any health problems they experience whether or not they are thought to be study related. Participants can report adverse events by using a link on the website, by e-mail and over the phone. All email messages contain a link to the adverse events reporting form and the study's toll-free number for reporting adverse events. After completing four weeks of the study and every eight weeks thereafter, participants are prompted to complete a survey on the website that asks about specific adverse events and symptoms. This information is closely monitored by project staff so that any patients who appear to be experiencing a potentially serious health-related problem can be contacted for further assessment and follow-up.

\section{Description of Measures and Data Collection Procedures}

Measures have been selected to assess our principal hypothesis that the proposed intervention will increase walking, as measured by step counts, among intervention patients relative to controls and reduce pain-related functional interference. Potential mediating factors, such as self-efficacy, and the benefits of a walking program, 


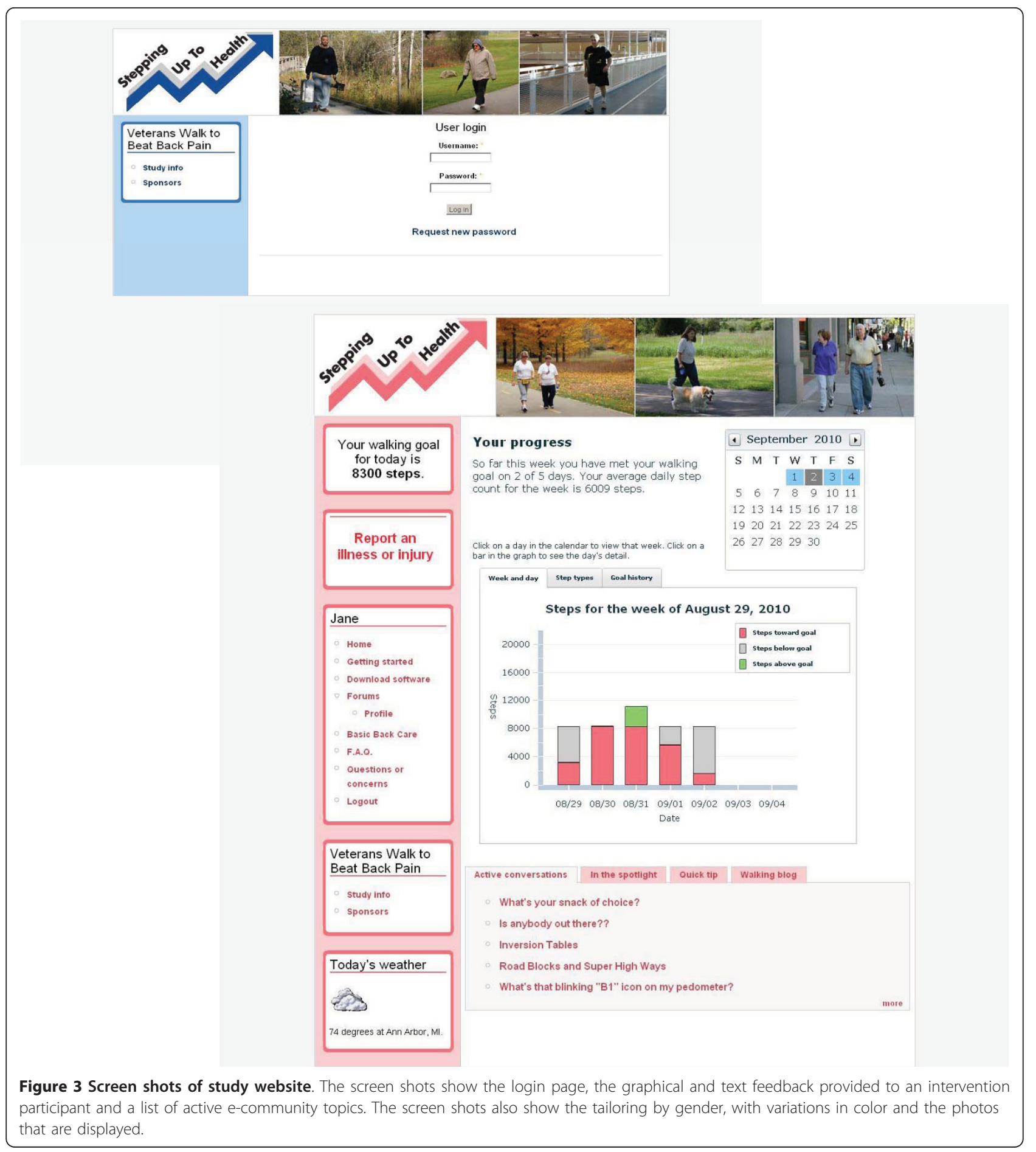

such as improvements in mood and quality of life, are also of significant interest. Data collection includes a computer-based survey completed at baseline, 6 months and 12 months, a six-minute walk test conducted at baseline and 12 months, and the step counts collected when participants upload their pedometer data. We are also collecting quantitative information about patients' use of the system via computerized records that the system maintains of all contacts. Health services use is assessed by patient report and by data obtained from the VA computerized medical record system.

The primary outcome for this study is pain-related disability and functional interference. Following the recommendations made through the Initiative on 
Methods, Measurement, and Pain Assessment in Clinical Trials (IMMPACT) [64], we are using both a disease-specific measure, the Roland and Morris Back Pain Disability Questionnaire (RDQ) index, and a generic measure of pain-related functioning from the medical outcomes study [65]. We hypothesize that the intervention will decrease back pain-related disability and pain-related functional interference. The RDQ index is a 24-item scale that has been widely used in back pain studies as a measure of self-perceived disability. The scale has good internal consistency, discriminative validity and is sensitive to change [66-69]. The medical outcomes study (MOS) pain measurement instrument assesses the effect of pain on mood and behaviors as well as the severity of pain over the past 4 weeks [65]. There is limited information about how the MOS instrument compares with other pain assessments but it is easily understood by patients and produces scales that have relatively good internal consistency [65].

Secondary outcomes include average daily steps, functional status, general health-related quality of life and pain intensity. Walking, which is a key aspect of the intervention, is measured as the number of average daily steps using the Omron HJ-720ITC pedometer. Rather than having to rely on self-reported step counts, the Omron allows us to upload the objectively recorded pedometer data directly to a database through the use of an embedded USB port. All data are time stamped by the pedometer. As an objective measure of function and to help validate the step count data obtained using the study pedometers we are conducting a six minute walk test at baseline and 12 months [70,71]. Participants are instructed to walk as far as they can in six minutes without running or jogging, with the primary measurement being the distance covered during those six minutes. Patients' general physical and mental functioning is being measured using the SF- $12^{\circ}$ Health Survey [72] and pain intensity is evaluated using a numeric rating scale with standardized anchors $(0=$ "no pain" and $10=$ "worst pain imaginable"), as used in the VHA's Pain as the Fifth Vital Sign initiative [73]. Patients use this scale to rate their current level of pain and their average level of pain during the past four weeks.

Other secondary outcomes and potential moderators include pain-related fear or kinesiophobia, which is being measured using a revised version of the Tampa Scale of Kinesiophobia (TSK-R) [74]; self-efficacy for exercise, which is being measured using the Exercise Regularly Scale [75]; the presence of depressive symptoms, which is assessed using a ten-item version of the Center for Epidemiologic Studies Depression Scale (CES-D 10) [76]; and, socio-demographic characteristics, such as age, gender and education level, other health conditions (e.g., diabetes), body mass index, perceived social support, health services utilization and employment status. Finally, an administrative interface to the website and database allows the study staff to track participant progress as well as ascertain whether a participant has been uploading step count data. This database will be used to assess participants' use of the different intervention components. For example, we will know how often the participant uploads step counts, how often they log on to the website, and whether they participate in the e-community.

\section{Analysis Plan}

The patient is the primary unit of analysis for this study. Our sample size calculation was based on the RDQ index as the primary endpoint with a minimally detectable effect size determined as a difference of 0.4 standard deviations (SD) based on published data $[68,77,78]$. To detect a difference of 0.4 SD with $80 \%$ power using a two-sided 0.05 level two-group t-test, we will enroll 130 subjects in each group, to allow for an attrition rate of $30 \%$ at one year and a sample with outcome data of 100 patients in each group.

To determine whether the intervention reduces painrelated functional interference we will compare the difference in the RDQ index at 12 months between the two groups using a linear mixed-effects model. Similarly, mixed-effects models will be used to assess the effect of the intervention on step counts, quality of life, pain intensity, pain related fear and self-efficacy for exercise. Identifying factors associated with a sustained increase in walking over a 12-month timeframe is an exploratory analysis within the intervention group.

In addition, to understand features of successful versus less successful intervention experiences, we will analyze data collected through our monitoring of participant system use and semi-structured interviews conducted with a purposeful sample of intervention participants (choosing a sample of eight who expressed high satisfaction with the intervention and/or improved walking and a sample of eight with poor satisfaction and/or outcomes). Using standard qualitative methods [79], we will identify central themes from these interviews associated with the success of the intervention.

The two major limitations of the study design are: (1) we will be unable to directly compare the effect of this intervention to the effects of other types of exercise programs that have demonstrated promise in randomized trials (e.g., Yoga); and (2) usual care patients will receive some intervention elements (e.g., they will receive a pedometer and some of the educational content). Nevertheless, we believe that the design represents the optimal compromise between scientific rigor and real-world practicality. Further, we expect that neither the pedometer nor the extra education will have a substantial 
influence on our primary outcome. If they do have any impact, the effect would be to reduce the likelihood of finding treatment differences between the control and intervention groups. Thus, the design for this study will provide rigorous evidence about the effectiveness of the proposed intervention, which is novel and has yet to be evaluated and determined to be effective in isolation, as well as information about possible implementation in other settings.

\section{Discussion}

Current evidence suggests that physical activity is one of the most effective strategies for managing chronic back pain and improving function $[16,19,25]$. Nonetheless, levels of physical activity are low among all segments of the U.S. population and especially individuals with chronic pain $[80,81]$. Despite the positive results of exercise observed in clinical trials little is known about how to effectively and efficiently assist patients with chronic conditions, and specifically those with unique challenges such as chronic back pain, with becoming more physically active and continuing to remain active over time. Given the positive benefits of exercise in managing chronic back pain and the significant need for effective strategies for increasing physical activity, the primary objective of this study is to assess the efficacy of a novel Internet and pedometer-based intervention that is designed to increase walking among individuals with chronic back pain, and thereby reduce pain-related disability and functional interference. Our hypothesis is that this intervention will increase activity levels, improve adherence to walking as needed to maintain the positive effects over time, and make exercise programs more accessible to a broad range of patients with chronic back pain.

\section{Acknowledgements \\ This project is funded through a grant from the Department of Veterans Affairs, Health Services Research and Development Service (IIR 07-177). The views expressed in this article are those of the authors and do not necessarily reflect the position or policy of the Department of Veterans Affairs. Dr. Piette is a VA Career Scientist and Dr. Richardson was supported in part by a career development award from NHLBI (K23HL075098) and a Physician Faculty Scholars Program award from the Robert Wood Johnson Foundation (57408). The authors would like to thank Robert Kerns, Jack Rosenberg and Robert Werner for their assistance during the design of this study as well as the Physical Therapy Service at the VA Ann Arbor Medical Center for their help during the conduct of the project.}

\section{Author details}

${ }^{1}$ VA Ann Arbor Health Services Research and Development Center of Excellence, VA Ann Arbor Healthcare System, Ann Arbor, MI, USA. ${ }^{2}$ Department of Internal Medicine, University of Michigan Medical School, Ann Arbor, MI, USA. ${ }^{3}$ Center for Statistical Consultation and Research, University of Michigan, Ann Arbor, MI, USA. ${ }^{4}$ Department of Family Medicine, University of Michigan Medical School, Ann Arbor, MI, USA.

\section{Authors' contributions}

SLK, JDP, EAK, HMK and CRR were involved in the conception and design of the study. TM, RK and $\mathrm{MH}$ are involved in study data collection. All authors were involved in drafting the manuscript and revising it for critically important content. All authors have read and approved the final manuscript.

\section{Competing interests}

The authors declare that they have no competing interests.

Received: 7 September 2010 Accepted: 13 September 2010 Published: 13 September 2010

\section{References}

1. Deyo RA, Mirza SK, Martin BI: Back pain prevalence and visit rates: estimates from U.S. national surveys, 2002. Spine 2006, 31(23):2724-2727.

2. Brooks PM: The burden of musculoskeletal disease-a global perspective. Clinical Rheumatology 2006, 25(6):778-781.

3. Lawrence RC, Helmick CG, Arnett FC, Deyo RA, Felson DT, Giannini EH, Heyse SP, Hirsch R, Hochberg MC, Hunder GG, et al: Estimates of the prevalence of arthritis and selected musculoskeletal disorders in the United States. Arthritis and Rheumatism 1998, 41(5):778-799.

4. Koes BW, van Tulder MW, Thomas S: Diagnosis and treatment of low back pain. BMJ 2006, 332(7555):1430-1434.

5. Andersson GB: Epidemiological features of chronic low-back pain. Lancet 1999, 354(9178):581-585.

6. Weiner DK, Haggerty CL, Kritchevsky SB, Harris T, Simonsick EM, Nevitt M, Newman A: How does low back pain impact physical function in independent, well-functioning older adults? Evidence from the Health ABC Cohort and implications for the future. Pain Medicine 2003, 4(4):311-320.

7. Jacobs JM, Hammerman-Rozenberg R, Cohen A, Stessman J: Chronic back pain among the elderly: prevalence, associations, and predictors. Spine 2006, 31(7):E203-207.

8. Druss BG, Marcus SC, Olfson M, Pincus HA: The most expensive medical conditions in America. Health Affairs 2002, 21(4):105-111.

9. Clark JD: Chronic pain prevalence and analgesic prescribing in a general medical population. Journal of Pain and Symptom Management 2002, 23(2):131-137

10. Kerns RD, Otis J, Rosenberg R, Reid MC: Veterans' reports of pain and associations with ratings of health, health-risk behaviors, affective distress, and use of the healthcare system. Journal of Rehabilitation Research and Development 2003, 40(5):371-379.

11. Crosby FE, Colestro J, Ventura MR, Graham K: Survey of pain among veterans in Western New York. Pain Manag Nurs 2006, 7(1):12-22.

12. Krein SL, Heisler M, Piette JD, Butchart A, Kerr EA: Overcoming the influence of chronic pain on older patients' difficulty with recommended self-management activities. The Gerontologist 2007, 47(1):61-68.

13. Butchart A, Kerr EA, Heisler M, Piette JD, Krein SL: Experience and management of chronic pain among patients with other complex chronic conditions. The Clinical journal of pain 2009, 25(4):293-298.

14. Gironda RJ, Clark ME, Massengale JP, Walker RL: Pain among veterans of Operations Enduring Freedom and Iraqi Freedom. Pain Medicine 2006, 7(4):339-343.

15. Sinnott $\mathrm{P}$, Wagner TH: Low Back Pain in VA Users. Archives of Internal Medicine 2009, 169(14):1338-1339.

16. Hayden JA, van Tulder MW, Malmivaara AV, Koes BW: Meta-analysis: exercise therapy for nonspecific low back pain. Annals of Internal Medicine 2005, 142(9):765-775.

17. Hayden JA, van Tulder MW, Tomlinson G: Systematic review: strategies for using exercise therapy to improve outcomes in chronic low back pain. Annals of Internal Medicine 2005, 142(9):776-785.

18. Lorig KR, Laurent DD, Deyo RA, Marnell ME, Minor MA, Ritter PL: Can a back pain E-mail discussion group improve health status and lower health care costs?: A randomized study. Archives of Internal Medicine 2002, 162(7):792-796.

19. van Tulder MW, Koes B, Malmivaara A: Outcome of non-invasive treatment modalities on back pain: an evidence-based review. Eur Spine J 2006, 15(Suppl 1):S64-81. 
20. Turk DC: Clinical effectiveness and cost-effectiveness of treatments for patients with chronic pain. The Clinical Journal of Pain 2002, 18(6):355-365.

21. Sherman KJ, Cherkin DC, Erro J, Miglioretti DL, Deyo RA: Comparing yoga, exercise, and a self-care book for chronic low back pain: a randomized, controlled trial. Annals of Internal Medicine 2005, 143(12):849-856.

22. Hoffman BM, Papas RK, Chatkoff DK, Kerns RD: Meta-analysis of psychological interventions for chronic low back pain. Health Psychol 2007, 26(1):1-9.

23. van Tulder MW, Koes B, Seitsalo S, Malmivaara A: Outcome of invasive treatment modalities on back pain and sciatica: an evidence-based review. Eur Spine J 2006, 15(Suppl 1):S82-92.

24. Weinstein JN, Lurie JD, Tosteson TD, Skinner JS, Hanscom B, Tosteson AN, Herkowitz H, Fischgrund J, Cammisa FP, Albert T, et al: Surgical vs nonoperative treatment for lumbar disk herniation: the Spine Patient Outcomes Research Trial (SPORT) observational cohort. JAMA 2006, 296(20):2451-2459.

25. Chou R, Huffman LH: Nonpharmacologic therapies for acute and chronic low back pain: a review of the evidence for an American Pain Society/ American College of Physicians clinical practice guideline. Annals of Internal Medicine 2007, 147(7):492-504.

26. Von Korff M, Balderson BH, Saunders K, Miglioretti DL, Lin EH, Berry S, Moore JE, Turner JA: A trial of an activating intervention for chronic back pain in primary care and physical therapy settings. Pain 2005, 113(3):323-330.

27. Smeets RJ, Vlaeyen JW, Hidding A, Kester AD, van der Heijden GJ, van Geel AC, Knottnerus JA: Active rehabilitation for chronic low back pain: Cognitive-behavioral, physical, or both? First direct post-treatment results from a randomized controlled trial [ISRCTN22714229]. BMC Musculoskeletal disorders 2006, 7(1):5.

28. Mailloux J, Finno M, Rainville J: Long-term exercise adherence in the elderly with chronic low back pain. American Journal of Physical Medicine \& rehabilitation/Association of Academic Physiatrists 2006, 85(2):120-126.

29. Friedrich M, Gittler G, Arendasy M, Friedrich KM: Long-term effect of a combined exercise and motivational program on the level of disability of patients with chronic low back pain. Spine 2005, 30(9):995-1000.

30. Mitchinson AR, Kerr EA, Krein SL: Management of chronic noncancer pain by VA primary care providers: when is pain control a priority? The American Journal of Managed Care 2008, 14(2):77-84

31. Barry LC, Kerns RD, Guo Z, Duong BD, lannone LP, Carrington Reid M: Identification of strategies used to cope with chronic pain in older persons receiving primary care from a Veterans Affairs Medical Center. Journal of the American Geriatrics Society 2004, 52(6):950-956.

32. Barry $L C$, Gill $T M$, Kerns RD, Reid MC: Identification of pain-reduction strategies used by community-dwelling older persons. The Journals of Gerontology 2005, 60(12):1569-1575.

33. Hendrick P, Te Wake AM, Tikkisetty AS, Wulff L, Yap C, Milosavljevic S: The effectiveness of walking as an intervention for low back pain: a systematic review. Eur Spine J 2010

34. Morey MC, Ekelund C, Pearson M, Crowley G, Peterson M, Sloane R, Pieper C, McConnell E, Bosworth H: Project LIFE: a partnership to increase physical activity in elders with multiple chronic illnesses. Journal of Aging and Physical Activity 2006, 14(3):324-343.

35. Goodrich DE, Larkin AR, Lowery JC, Holleman RG, Richardson CR: Adverse events among high-risk participants in a home-based walking study: a descriptive study. Int I Behav Nutr Phys Act 2007, 4(1):20.

36. Richardson CR, Brown BB, Foley S, Dial KS, Lowery JC: Feasibility of adding enhanced pedometer feedback to nutritional counseling for weight loss. Journal of Medical Internet Research 2005, 7(5):e56.

37. Rhudy JL, Dubbert PM, Kirchner KA, Williams AE: Efficacy of a program to encourage walking in VA elderly primary care patients: The role of pain. Psychology, Health \& Medicine 2007, 12(3):289-298.

38. Dubbert PM, Cooper KM, Kirchner KA, Meydrech EF, Bilbrew D: Effects of nurse counseling on walking for exercise in elderly primary care patients. The Journals of Gerontology 2002, 57(11):M733-740.

39. Wilcox S, King AC, Brassington G, Ahn D: Physical activity preferences of middle-aged and older adults: a community analysis. J Aging Phys Activity 1999, 7:386-399

40. King AC, Haskell WL, Taylor CB, Kraemer HC, DeBusk RF: Group- vs homebased exercise training in healthy older men and women. A community-based clinical trial. JAMA 1991, 266(11):1535-1542.
41. Tudor-Locke C, Ham SA, Macera CA, Ainsworth BE, Kirtland KA, Reis JP Kimsey CD Jr: Descriptive epidemiology of pedometer-determined physical activity. Medicine and Science in Sports and exercise 2004, 36(9):1567-1573.

42. Richardson CR, Faulkner G, McDevitt J, Skrinar GS, Hutchinson DS, Piette JD: Integrating physical activity into mental health services for persons with serious mental illness. Psychiatric Services 2005, 56(3):324-331.

43. Bravata DM, Smith-Spangler C, Sundaram V, Gienger AL, Lin N, Lewis $R$, Stave CD, Olkin I, Sirard JR: Using pedometers to increase physical activity and improve health: a systematic review. JAMA 2007, 298(19):2296-2304.

44. Baranowski T, Cullen KW, Nicklas T, Thompson D, Baranowski J: Are current health behavioral change models helpful in guiding prevention of weight gain efforts? Obesity Research 2003, 11(Suppl):23S-43S.

45. Brawley LR, Rejeski WJ, King AC: Promoting physical activity for older adults: the challenges for changing behavior. American Journal of Preventive Medicine 2003, 25(3 Suppl 2):172-183.

46. Bandura A: Self-Efficacy: The Exercise of Control. New York, NY: W.H. Freeman and Company 1997.

47. Tate DF, Jackvony EH, Wing RR: A randomized trial comparing human email counseling, computer-automated tailored counseling, and no counseling in an Internet weight loss program. Archives of Internal Medicine 2006, 166(15):1620-1625.

48. Lorig KR, Ritter PL, Laurent DD, Plant K: Internet-based chronic disease self-management: a randomized trial. Medical Care 2006, 44(11):964-971.

49. Napolitano MA, Fotheringham M, Tate D, Sciamanna C, Leslie E, Owen N, Bauman A, Marcus B: Evaluation of an internet-based physical activity intervention: a preliminary investigation. Ann Behav Med 2003, 25(2):92-99.

50. Stiggelbout M, Hopman-Rock M, Crone M, Lechner L, van Mechelen W: Predicting older adults' maintenance in exercise participation using an integrated social psychological model. Health Education Research 2006, 21(1):1-14

51. Dominick KL, Morey M: Adherence to Physical Activity. In Patient Treatment Adherence concepts, Interventions, and Measurement. Edited by: Bosworth HB, Oddone EZ, Weinberger M. Mahwah, NJ: Lawrence Erlbaum Associates, Inc; 2006:49-93.

52. Rejeski WJ, Brawley LR, Ambrosius WT, Brubaker PH, Focht BC, Foy CG, Fox LD: Older adults with chronic disease: benefits of group-mediated counseling in the promotion of physically active lifestyles. Health Psychol 2003, 22(4):414-423.

53. Lorig KR, Sobel DS, Ritter PL, Laurent D, Hobbs M: Effect of a selfmanagement program on patients with chronic disease. Eff Clin Pract 2001, 4(6):256-262

54. Von Korff M, Moore JE, Lorig K, Cherkin DC, Saunders K, Gonzalez VM, Laurent $D$, Rutter $C$, Comite F: A randomized trial of a lay person-led selfmanagement group intervention for back pain patients in primary care. Spine 1998, 23(23):2608-2615.

55. Denison E, Asenlof P, Lindberg P: Self-efficacy, fear avoidance, and pain intensity as predictors of disability in subacute and chronic musculoskeletal pain patients in primary health care. Pain 2004 111(3):245-252.

56. Tate DF, Jackvony EH, Wing RR: Effects of Internet behavioral counseling on weight loss in adults at risk for type 2 diabetes: a randomized trial. JAMA 2003, 289(14):1833-1836.

57. House JS, Landis KR, Umberson D: Social relationships and health. Science 1988, 241(4865):540-545

58. Trost SG, Owen N, Bauman AE, Sallis JF, Brown W: Correlates of adults' participation in physical activity: review and update. Medicine and Science in Sports and Exercise 2002, 34(12):1996-2001.

59. Schwartz CE, Sendor M: Helping others helps oneself: response shift effects in peer support. Social Science \& Medicine (1982) 1999, 48(11):1563-1575.

60. Arnstein P, Vidal M, Wells-Federman C, Morgan B, Caudill M: From chronic pain patient to peer: benefits and risks of volunteering. Pain Manag Nurs 2002, 3(3):94-103.

61. Lee M, Kim M, Bascola M, Kalck K, Bendis K, Zhu W: Position invariance of Omron-BI pedometers: a preliminary study (abstract). Proceedings of the the Walking for Health: Measurement and Research Issues and Challenges Urbana-Champaign, IL 2005. 
62. Crouter SE, Schneider PL, Bassett DR Jr: Spring-levered versus piezoelectric pedometer accuracy in overweight and obese adults. Medicine and Science in Sports and Exercise 2005, 37(10):1673-1679.

63. Richardson CR, Mehari KS, McIntyre LG, Janney AW, Fortlage LA, Sen A, Strecher VJ, Piette JD: A randomized trial comparing structures and lifestyle goals in an internet-mediated walking program for people with type 2 diabetes. Int J Behav Nutr Phys Act 2007, 4(1):59.

64. Dworkin RH, Turk DC, Farrar JT, Haythornthwaite JA, Jensen MP, Katz NP, Kerns RD, Stucki G, Allen RR, Bellamy N, et al: Core outcome measures for chronic pain clinical trials: IMMPACT recommendations. Pain 2005, 113(12):9-19.

65. Ware JE Jr, Sherbourne CD: The MOS 36-item short-form health survey (SF-36). I. Conceptual framework and item selection. Medical Care 1992, 30(6):473-483.

66. Roland M, Morris R: A study of the natural history of back pain. Part I: development of a reliable and sensitive measure of disability in lowback pain. Spine 1983, 8(2):141-144.

67. Roland M, Fairbank J: The Roland-Morris Disability Questionnaire and the Oswestry Disability Questionnaire. Spine 2000, 25(24):3115-3124.

68. Riddle DL, Stratford PW, Binkley JM: Sensitivity to change of the RolandMorris Back Pain Questionnaire: part 2. Physical Therapy 1998, 78(11):1197-1207.

69. Hsieh CY, Phillips RB, Adams AH, Pope MH: Functional outcomes of low back pain: comparison of four treatment groups in a randomized controlled trial. Journal of Manipulative and Physiological Therapeutics 1992, 15(1):4-9.

70. Enright PL: The six-minute walk test. Respiratory care 2003, 48(8):783-785.

71. Redelmeier DA, Bayoumi AM, Goldstein RS, Guyatt GH: Interpreting small differences in functional status: the Six Minute Walk test in chronic lung disease patients. American Journal of Respiratory and Critical Care Medicine 1997, 155(4):1278-1282.

72. Ware J Jr, Kosinski M, Keller SD: A 12-Item Short-Form Health Survey: construction of scales and preliminary tests of reliability and validity. Medical Care 1996, 34(3):220-233.

73. Mularski RA, White-Chu F, Overbay D, Miller L, Asch SM, Ganzini L: Measuring pain as the 5 th vital sign does not improve quality of pain management. J Gen Intern Med 2006, 21(6):607-612.

74. Gironda RJ, Clark ME, Young RW: A confirmatory factor analysis of the Tampa Scale of Kinesiophobia- Revised. Poster session presented at 22nd Annual Meeting of the American Pain Society. Chicago, IL 2003.

75. Lorig K, Stewart A, Ritter P, Gonzalez V, Laurent D, Lynch J: Outcome measures for health education and other health care interventions. Thousand Oaks, CA: Sage Publications 1996.

76. Andresen EM, Malmgren JA, Carter WB, Patrick DL: Screening for depression in well older adults: evaluation of a short form of the CES-D (Center for Epidemiologic Studies Depression Scale). American Journal of Preventive Medicine 1994, 10(2):77-84.

77. Patrick DL, Deyo RA, Atlas SJ, Singer DE, Chapin A, Keller RB: Assessing health-related quality of life in patients with sciatica. Spine 1995, 20(17):1899-1908, discussion 1909.

78. Davidson M, Keating JL: A comparison of five low back disability questionnaires: reliability and responsiveness. Physical Therapy 2002, 82(1):8-24

79. Crabtree B, Miller W: Doing Qualitative Research. Thousand Oaks, CA: Sage Publications 1999.

80. Brown DR, Yore MM, Ham SA, Macera CA: Physical activity among adults $>$ or $=50 \mathrm{yr}$ with and without disabilities, BRFSS 2001. Medicine and Science in Sports and Exercise 2005, 37(4):620-629.

81. Elfving B, Andersson T, Grooten WJ: Low levels of physical activity in back pain patients are associated with high levels of fear-avoidance beliefs and pain catastrophizing. Physiother Res Int 2007, 12(1):14-24.

Pre-publication history

The pre-publication history for this paper can be accessed here: http://www.biomedcentral.com/1471-2474/11/205/prepub

doi:10.1186/1471-2474-11-205

Cite this article as: Krein et al: Veterans walk to beat back pain: study rationale, design and protocol of a randomized trial of a pedometerbased Internet mediated intervention for patients with chronic low back pain. BMC Musculoskeletal Disorders 2010 11:205.

\section{Submit your next manuscript to BioMed Central and take full advantage of:}

- Convenient online submission

- Thorough peer review

- No space constraints or color figure charges

- Immediate publication on acceptance

- Inclusion in PubMed, CAS, Scopus and Google Scholar

- Research which is freely available for redistribution 